\title{
RELAÇÕES DE TRABALHO E CAUSAS RECLAMATÓRIAS: UM DESAFIO PARA A GESTÃO DE PESSOAS
}

DOI: http://dx.doi.org/10.18616/pers09

Katia Nunes - Unesc

E-mail: katiarickennunes@hotmail.com

Gisele Silveira Coelho Lopes - Unesc

E-mail: giselelopes@unesc.net

Fernanda Nunes Peruchi - Unesc

E: mail: fernandan.peruchi@gmail.com 


\section{INTRODUÇÃO}

O número de Instituições de Ensino Superior (IES) no Brasil vem crescendo a cada ano, conforme dados do Censo da Educação Superior. Em 2013 existiam no Brasil 1.859 IES. Em 2004, eram 2.013 instituições e, em 2015, chegou-se ao número de 2.364 instituições, significando um crescimento de $21,36 \%$, em número de instituições de 2003 a 2013 (INEP, 2015).

Levando em consideração a instalação de 505 novas instituições de ensino superior entre 2003 a 2015, o quadro funcional das Universidades também se amplia proporcionalmente, tendo a necessidade de compor em sua estrutura organizacional professores, técnicos-administrativos, seguranças, profissionais da área de manutenção, entre outros, para dar o suporte funcional e administrativo na prestação dos serviços (INEP, 2015). A educação nos últimos anos tornou-se promissora economicamente, pois possui características específicas como qualquer outro empreendimento. $\mathrm{O}$ que reforça é o número de matrículas realizadas entre os anos de 2010-2015, que cresceu em média 31,77\%. Na rede pública, o crescimento de matrículas foi de $25,11 \%$ e na rede privada de $33,91 \%$. Vale evidenciar que, esse crescimento requer o aumento de professores em regime de tempo integral, número de colaboradores dos setores administrativos para dar suporte às demandas existentes (INEP, 2015).

Com o aumento no número de matrículas nas Instituições de Ensino Superior, o controle das atividades desenvolvidas pelos colaboradores envolvidos no processo tornou-se mais complexo. A dificuldade de gerenciamento aumenta na mesma proporção que novos incrementos são adicionados ao quadro funcional. Quanto maior a instituição, menor o controle do processo. Isso se justifica quando há muitos subordinados para a mesma chefia, o que dificulta o processo gerencial (OLIVARES, 2002).

Como qualquer organização, as Universidades também precisam gerenciar seus recursos humanos. Para isso, é importante firmar com os colaboradores, além dos contratos formais de trabalho, os contratos psicológicos. Marras (2005) afirma que o contrato psicológico é aquele que estabelece os deveres e responsabilidades, tanto por parte da organização como por parte do colaborador. Quando uma das partes não cumpre com suas obrigações, surgem os conflitos, que, se não forem bem administrados, podem prejudicar a relação entre os envolvidos. Quando a frustração acontece por parte dos colaboradores, os reflexos são perceptíveis na rotatividade de pessoal, no absenteísmo, na insatisfação com o ambiente de trabalho, na redução da qualidade e na baixa produtividade. 
Desse modo, cabe aos gestores de recursos humanos buscarem alternativas para minimizar as frustrações dos colaboradores, pois se as frustrações não forem administradas poderão resultar em elevados índices de reclamatórias trabalhistas. Estas reclamatórias trabalhistas tendem a prejudicar a imagem e a reputação da empresa no mercado por muito tempo (MACHADO, 2007). Diante desses fatos é que surge a necessidade de um olhar humanístico, não só da área de recursos humanos, mas também de todos os gestores em relação aos colaboradores, correlacionando os interesses das empresas com as necessidades humanas do trabalhador.

Frente a esses pressupostos, foi possível perceber uma lacuna na literatura de estudos que provoquem a reflexão de reclamatórias trabalhistas com uma lente na gestão de pessoas. O que se encontra são estudos direcionados ao direito do trabalho que transcorrem o que a lei prediz, porém não discutem a corresponsabilidade da gestão de pessoas em minimizar as causas reclamatórias que são ajuizadas por colaboradores descontentes com a cultura e a política organizacional preexistente, reprovável pela legislação, que poderiam ser evitadas.

É a partir da falta de informações referentes às causas de reclamatórias trabaIhistas no Brasil que este trabalho se debruça. $O$ objetivo deste estudo foi conhecer as causas de reclamatórias trabalhistas ajuizadas no ano de 2010 a 2011 contra uma Instituição de Ensino Superior localizada na região sul de Santa Catarina.

Portanto, este trabalho introduz apresentando um preâmbulo das instituições de ensino superior e suas complexidades organizacionais. Na segunda seção, é apresentada a revisão teórica que contextualiza temas relacionados à gestão de pessoas e às relações de trabalho, reclamatórias trabalhistas e situações que resultam em perdas trabalhistas. Na sequência, é definida a metodologia utilizada para a coleta dos dados e, em seguida, a análise dos dados da pesquisa, dividindo as etapas da seguinte forma: a) características dos setores, b) pedidos indenizatórios, c) procedência das causas trabalhistas, d) os custos gerados pelas reclamatórias, e por fim e) discussão dos resultados e sugestões.

\section{REVISÃO TEÓRICA}

\section{GESTÃO DE PESSOAS E AS RELAÇÕES DE TRABALHO}

As relações de trabalho tiveram início no período da revolução industrial, um período marcado pela exploração de mulheres e crianças e o desenvolvimento do trabalho assalariado. Com o crescimento do mercado de trabalho nesse período, 
houve a necessidade do equilíbrio entre o capital e o trabalho. Esse equilíbrio era necessário para amenizar a precariedade das condições de trabalho e a proteção do trabalhador, fatos que marcaram o início do direito do trabalho (PONTELO; CRUZ, 2006).

Insta observar que as relações de trabalho podem ser definidas como todas as relações entre empregados e empregadores dentro das organizações. A perspectiva da Administração considera as relações de trabalho um enfoque para a área de recursos humanos. Isso significa que a área de recursos humanos não se limita apenas aos aspectos administrativos e formais, mas é corresponsável pelo acompanhamento e desenvolvimento das relações sociais nas organizações (SIQUEIRA, 1998).

Impulsionadas pela modernização e o crescente desenvolvimento econômico mundial, as empresas tiveram que repensar as formas de gerir pessoas e processos. Foi necessária uma ressignificação da organização do trabalho e a inserção dos colaboradores como importantes no desenvolvimento dos processos, além da criação de incentivos não monetários que visassem o envolvimento dos colaboradores no alcance das metas organizacionais (JOSKO, 2004).

Frente a esses pressupostos, a gestão de pessoas possui diversas atividades que precisam ser realizadas de forma integrada para buscar o aperfeiçoamento constante na forma de gestão, que influencia diretamente nas relações de trabaIho, pois impacta no modo como o empregado vê a empresa e como a empresa vê o empregado. A busca contínua de um ambiente organizacional agradável, bem como com pessoas satisfeitas e realizadas é o que faz com que o desempenho da empresa transpareça e seja um diferencial no mercado de trabalho. Para que isso aconteça é importante que haja uma sintonia entre as políticas de recursos humanos e a cooperação ativa dos colaboradores. Essa sintonia busca um objetivo comum que é implantar de forma segura, intensa e coordenada vínculos de segurança na relação de trabalho com o colaborador (JORGE et al., 2007).

Diante do exposto é que nasce a necessidade da busca de novos incrementos nas metodologias já existentes das relações de trabalho, assim procura-se unificar velhas práticas eficazes com novas metodologias que tendem a sanar os problemas complexos da gestão de pessoas e atender aos novos padrões de gerir pessoas voltadas para o lado humanístico (BORGES, 2004). 


\section{RECLAMATÓRIAS TRABALHISTAS E SITUAÇÕES QUE RESULTAM EM PERDAS TRABALHISTAS}

Quando um funcionário se sente lesado, é natural que procure a Justiça para que sejam revistos seus direitos. No processo de reivindicação, o lesado faz o uso da reclamatória trabalhista, uma ação judicial que pode ser movida contra uma empresa ou equiparada à empresa, desde que tenha existido relação de emprego expressa ou tacitamente entre empregador e empregado (FENASERA, 2012).

Nem sempre todas as expectativas alimentadas são realmente cumpridas, o que causa um descontentamento entre os pares. Passada esta fase, naturalmente as relações se tornam mais controladas. O colaborador é percebido pela empresa como possível reclamante gerando certo grau de desconfiança, a ponto de aumentar as chances da empresa responder judicialmente por seus atos. Toda essa situação, além do desconforto para os envolvidos, ocasiona fatores como aumento na rotatividade e absenteísmo, desmotivação, desrespeito às chefias, conflitos, baixa produtividade e queda do desempenho das funções (METZ, 2003).

Nesse aspecto, o papel da área de Recursos Humanos de uma empresa é fundamental, pois por intermédio desta é que os gestores deverão obter auxílio e informações sobre a melhor forma de resolução de conflitos. Por isso, é aconseIhável que o setor de RH analise a situação de forma imparcial e, caso necessário, chame a atenção do gestor ou do colaborador (METZ, 2003).

A prevenção de perdas trabalhista precisa ser constante. Para isso, Marras (2005) defende a importância da manutenção do contrato psicológico, da preocupação da credibilidade da empresa frente aos empregados, da manutenção da motivação dos mesmos, do estabelecimento de medidas de prevenção e da percepção dos conflitos a tempo de serem resolvidos e neutralizados. Bernstein (1997) menciona um assunto que vem ao encontro da prevenção de perdas trabaIhistas, que é o gerenciamento de risco nas instituições. Segundo o autor, o gerenciamento de risco é a habilidade de identificar situações problemas que venham a surgir futuramente e transformá-las em oportunidades no presente. Essa atividade exige constante monitoramento das diversas ações tomadas dentro da empresa, uma vez que toda ação gera uma reação, e nem sempre a reação será positiva, podendo surtir efeitos indesejados que poderiam ser evitados. Vale ainda mencionar, segundo Santos (2002), a importância de a empresa adotar procedimentos padrões para prevenção e identificação de riscos internos e externos que possam interferir no seu bom andamento e no sucesso da instituição. 
Nessa linha de raciocínio, qualquer empresa precisa, para desenvolver suas tarefas, estabelecer relações de trabalho com seus empregados. Essas relações precisam ser regradas por pressupostos legais e jurídicos que estipulam direitos e deveres que devem ser seguidos à risca a fim de evitar reclamatórias trabalhistas (METZ, 2003). As reclamatórias trabalhistas podem nascer de pequenos descuidos, por alguma falha de gestão ou até mesmo pelo uso incorreto da legislação e normas trabalhistas. Por isso, ressalta-se a importância do conhecimento e práticas, bem como a atualização constante dos procedimentos a serem adotados dentro da organização (ZANCHETTA, 2007).

Dentro desse cenário é que se encontram algumas rotinas que, frequentemente, são alvos de reclamatórias trabalhistas, e que por esse motivo precisam de um olhar especial dos gestores e da área de Recursos Humanos, conforme demonstra o quadro 1. 
Quadro 1 - Descrição das normas trabalhistas

\begin{tabular}{|c|c|}
\hline $\begin{array}{c}\text { NORMAS } \\
\text { TRABALHISTAS }\end{array}$ & DESCRIÇÃO \\
\hline $\begin{array}{l}\text { Jornada } \\
\text { de trabalho } \\
\text { (Art. } 58 \text { e } 71 \text { da } \\
\text { CLT) }\end{array}$ & $\begin{array}{l}\text { a) A jornada de trabalha normal não excederá a oito horas diárias; } \\
\text { b) Empresas com número maior que } 10 \text { funcionários é obrigatório o registro de } \\
\text { entradas e saídas, com assinatura do cartão ponto pelo empregado; } \\
\text { c) Nas jornadas superiores a seis horas o período de descanso deve ser de no mínimo } \\
\text { uma hora e no máximo duas horas, salvo acordo escrito ou contrato coletivo. Nas } \\
\text { jornadas acima de quatros horas e inferiores a seis horas, o intervalo de descanso } \\
\text { deverá ser no mínimo quinze minutos. }\end{array}$ \\
\hline $\begin{array}{l}\text { Horas extras } \\
\text { (Art. } 59 \mathrm{da} \text { CLT) }\end{array}$ & $\begin{array}{l}\text { a) A hora extra não poderá exceder o limite máximo de duas horas diárias; } \\
\text { b) A remuneração das horas extras deverá ser pelo menos com acréscimo de } 50 \% \text {, ou } \\
\text { ser utilizado compensação por meio de acordo ou convenção coletiva, em que as horas } \\
\text { suplementares de um dia, serão compensadas em outro; } \\
\text { c) No caso de rescisão de contrato, as horas extras ainda não compensadas, deverão } \\
\text { obrigatoriamente ser pagas, e calculadas conforme o salário vigente na data rescisão; } \\
\text { d) A empresa deve adotar procedimentos para pagamento ou compensação das horas } \\
\text { extras de acordo com os dispositivos da CLT e convenção coletiva do sindicato a qual } \\
\text { pertença. }\end{array}$ \\
\hline $\begin{array}{l}\text { Adicional Noturno } \\
\text { (Art. } 73 \text { da CLT) }\end{array}$ & $\begin{array}{l}\text { a) Considera-se noturno o trabalho executado entre } 22 \text { horas de um dia e às } 5 \text { horas do dia } \\
\text { seguinte. } \\
\text { b) A remuneração do trabalho noturno terá acréscimo de } 20 \% \text { sobre a hora diurna, e } \\
\text { será computada reduzida com } 52 \text { minutos e } 30 \text { segundos. }\end{array}$ \\
\hline $\begin{array}{l}\text { Férias } \\
\text { (Art. } 130 \text { da CLT) }\end{array}$ & $\begin{array}{l}\text { a) Todo empregado terá direito anualmente ao gozo de um período de férias, sem } \\
\text { prejuízo da remuneração. Para fazer jus às férias, o empregado deverá ter o período } \\
\text { aquisitivo completo (ter trabalhado durante doze meses); após esse prazo inicia o } \\
\text { período concessivo (período de doze meses subsequentes em que o empregador deverá } \\
\text { conceder as férias); a intenção das férias é o descanso, por isso é ilegal que o } \\
\text { funcionário trabalhe durante seu período férias; } \\
\text { b) O funcionário poderá requerer } 15 \text { (quinze) dias antes do término do período } \\
\text { aquisitivo, converter } 1 / 3 \text { do período de férias a quem tem direito, em abono pecuniário, } \\
\text { reduzindo o período de gozo e recebendo por estes dias; } \\
\text { c) É devido ao empregado no período de férias o salário normal, acrescido de } 1 / 3 \text {, que } \\
\text { deverão ser pagos com dois dias de antecedência do início do gozo das férias. Se as férias } \\
\text { forem concedidas após vencimento do período concessivo, a remuneração deverá ser paga } \\
\text { em dobro. } \\
\text { d) O gozo de férias poderá em casos excepcionais ser concedido em dois períodos, } \\
\text { desde que o menor não seja inferior a dez dias. e) A comunicação da concessão de } \\
\text { férias deve ser realizada pelo empregador ao empregado, com no mínimo trinta dias de } \\
\text { antecedência por escrito. E antes do início do gozo de férias deverá ser anotado na } \\
\text { Carteira de Trabalho e na ficha de registro de empregado. } \\
\text { e) No caso de rescisão de contrato, salvo quando for demissão por justa causa, o } \\
\text { empregado receberá remuneração relativa às férias incompletas, na proporção de } 1 / 12 \\
\text { (um doze avos) por mês de serviço trabalhado ou fração superior a quatorze dias. }\end{array}$ \\
\hline $\begin{array}{l}\text { Adicional de } \\
\text { insalubridade e uso } \\
\text { de EPI } \\
\text { (Art. 189 da CLT) }\end{array}$ & $\begin{array}{l}\text { a) É obrigação da empresa, fornecer gratuitamente, os equipamentos de proteção } \\
\text { individual em perfeito estado de funcionamento, fornecer instruções de uso e de } \\
\text { precauções, a fim de evitar acidentes de trabalho ou doenças ocupacionais, e fiscalizar } \\
\text { o uso efetivo pelos empregados dos EPIs. A insalubridade poderá ser eliminada ou } \\
\text { neutralizada com ações que mantenham o ambiente de trabalho dentro dos limites de } \\
\text { tolerância, e com a utilização de equipamento de proteção individual que mantenham o } \\
\text { trabalhador protegido ao agente agressivo no limite de tolerância. }\end{array}$ \\
\hline $\begin{array}{l}\text { Adicional de } \\
\text { insalubridade e uso } \\
\text { de EPI } \\
\text { (Art. 189 da CLT) }\end{array}$ & $\begin{array}{l}\text { b) Mesmo depois de tomadas as providências pela empresa a respeito da insalubridade, } \\
\text { se houver trabalho em condições insalubres, acima dos limites de tolerâncias } \\
\text { estabelecidos pelo Ministério do Trabalho, o trabalhador fará jus ao pagamento do } \\
\text { adicional de insalubridade, conforme o grau em que se enquadra, de quarenta por cento } \\
\text { para grau máximo, vinte por cento para grau médio, e dez por cento para grau mínimo } \\
\text { sobre o salário mínimo. }\end{array}$ \\
\hline $\begin{array}{l}\text { Dano Moral } \\
\text { Art. } 5^{\circ} \text { da CF) }\end{array}$ & $\begin{array}{l}\text { a) O dano moral pode ser definido como a ofensa ou violação da ordem moral de uma } \\
\text { pessoa, refletindo em sua liberdade, sua honra, sua saúde e a sua imagem. O } \\
\text { trabalhador poderá solicitar reparação por dano moral, quando entender que foi lesado } \\
\text { a sua imagem, sua privacidade, sua moral. Esse é um item de difícil comprovação para } \\
\text { ambas as partes, por ser algo abstrato. }\end{array}$ \\
\hline
\end{tabular}

Fonte: Garcia (1999), Gonçalves (2005), Costa, Ferrari e Martins (2007) e Lório (2008). 
No quadro 1, foram apresentadas algumas normas trabalhistas com suas principais diretrizes, que, se seguidas corretamente, podem prevenir as reclamatórias trabalhistas. Vale ressaltar que os direitos dos trabalhadores, como o direito a férias, devem ser preservados para que se evite a desmotivação dos colaboradores e futuros conflitos (PONTELO; CRUZ, 2006).

Um ponto digno de nota é que as pessoas passam a maior parte de seu tempo em função do trabalho, uma vez que precisam deste para sobreviver. $O$ trabalho influencia em vários aspectos da vida das pessoas, como pessoais, financeiros, familiares, assim como as pessoas influenciam no sucesso das organizações. Por esse motivo é que itens como horas extras, realização de trabalho noturno e condutas ofensivas podem gerar transtornos, tanto para o colaborador quanto para a empresa. Diante desse contexto, é importante a avaliação da forma como o trabalho está sendo desenvolvido, a fim de saber qual será a opção mais vantajosa para ambas as partes (SIQUEIRA, 1998; MACHADO, 2007).

\section{PROCEDIMENTOS METODOLÓGICOS}

A pesquisa utilizada quanto aos fins de investigação foi descritiva, pois o objetivo deste estudo é conhecer as causas de reclamatórias trabalhistas ajuizadas no período de 2010 a 2011 contra uma Instituição de Ensino Superior localizada na região sul de Santa Catarina. Para isso, após a coleta dos dados, foi necessário descrever os achados. Quanto aos meios de investigação, foi utilizada a pesquisa documental. As informações foram obtidas nos documentos da instituição em estudo nos processos ajuizados sobre reclamatórias trabalhistas.

A pesquisa em questão foi desenvolvida em uma Instituição de Ensino Comunitária, localizada no estado de Santa Catarina com mais de 40 anos de fundação. Possui em seu quadro cerca de 1.000 funcionários, dentre eles professores e funcionários técnico-administrativos, que, juntamente, prestam serviços para aproximadamente 10.000 alunos, no âmbito do ensino fundamental e médio, ensino superior de graduação, especialização, mestrado e doutorado.

Para a coleta de dados foi utilizada a técnica de análise de conteúdo, que é uma forma de estudar, analisar e avaliar os objetos de estudo, neste caso, as reclamatórias trabalhistas. Em conjunto com a análise de conteúdo, foi realizada a análise documental nos documentos em arquivo na Instituição.

Na técnica de análise dos dados obtidos, foi utilizada a abordagem qualitativa, pois proporciona ao pesquisador uma análise do cenário real, interpretando e 
buscando descrever o problema em questão. Vale ainda evidenciar que, atrelada à análise de conteúdo, os pesquisadores leram todas as reclamatórias trabalhistas ajuizadas entre 2010 e 2011 para obter as informações inerentes ao objeto de pesquisa. O processo de análise consistiu na leitura minuciosa de todos os processos ajuizados no período citado. Na etapa de leitura, foi considerado o conteúdo dos depoimentos e argumentos dos reclamantes e do réu. Nesse sentido, os depoimentos serviram para a compreensão das reclamatórias ajuizadas nesse período, bem como das causas que demandaram as mesmas.

\section{RESULTADOS E DISCUSSÃO}

Essa seção está estruturada em três subseções, em que, primeiramente, são apresentadas as características dos setores que ajuizaram as reclamatórias trabaIhistas entre os anos de 2010 e 2011; em seguida, são apresentados os pedidos indenizatórios solicitados nas reclamatórias e os motivos que provocaram tais reivindicações. Como forma de compreender melhor cada pedido indenizatório, foi analisada a procedência das causas em relação ao número de citações das reclamatórias nos processos, e, por fim, o custo direto que gerou para a instituição nos dois anos de análise.

\section{a) Características dos Setores}

Para obter as informações sobre os setores foram utilizados e analisados os documentos processuais das reclamatórias trabalhistas ajuizadas entre os anos de 2010 e 2011. Foram identificadas 35 reclamatórias ajuizadas contra uma Instituição de Ensino Superior em estudo nesse período. A análise foi baseada nas características das reclamatórias, o setor de trabalho, os pedidos indenizatórios e os valores das causas. Para uma melhor visualização dos dados da pesquisa, os setores foram distribuídos em três grupos distintos: cursos de graduação, setor de apoio logístico e os setores administrativos. Esses grupos são apresentados na tabela 1.

Tabela 1 - Setores das reclamatórias trabalhistas

\begin{tabular}{lll}
\hline Setores & Freq. & \% \\
\hline Cursos de graduação & 17 & 48,6 \\
Apoio Logístico & 12 & 34,3 \\
Setores Administrativos & 6 & 17,1 \\
\hline Total & $\mathbf{3 5}$ & $\mathbf{1 0 0 , 0}$ \\
\hline
\end{tabular}

Fonte: Dados da pesquisa. 
Analisando a tabela 1 foi possível observar que os cursos de graduação ficaram com $48,6 \%$ das reclamatórias ajuizadas, distribuídas entre oito cursos, coordenados por gestores distintos. Nesse setor, é possível dizer que nas Instituições de Ensino Superior (IES), a predominância de colaboradores é no cargo de professor, quando analisando os dados referentes aos cursos de graduação. O professor é considerado peça chave para o bom desempenho da instituição, pois sem ele não existiria a empresa em questão. Partindo da premissa que o insumo principal, nesse caso, é a educação e o conhecimento transferido aos acadêmicos, é que se ressalta a importância de que esses profissionais estejam motivados e se sintam valorizados para que possam obter um bom desempenho no trabalho.

Na pesquisa realizada, constatou-se que nos cursos de graduação apenas profissionais ocupantes do cargo de professor foram os que ajuizaram as reclamatórias. É interessante ressaltar a preocupação com essa categoria de profissionais; pode ser a que necessite de maior atenção imediata, considerando uma frequência maior em relação aos outros grupos analisados. Em geral, essa categoria desempenha atividades de ensino, pesquisa, extensão e atividades administrativas, dentro e fora da Instituição, o que é o caso de muitos professores que possuem mais de um local de trabalho como fonte de renda. Pela atividade que exercem, o grau de instrução desses profissionais é elevado e com tendência de crescimento contínuo, o que evidencia que esses têm um maior conhecimento sobre direitos, deveres e práticas trabalhistas, o que os tornam indivíduos mais questionadores.

O setor de Apoio Logístico ficou com 34,3\% das reclamatórias, sendo esse um setor com suas peculiaridades, diferenciado dos outros grupos, e está concentrado sob a direção de um gerente e um supervisor. Esse setor é responsável pela higiene, limpeza e organização do patrimônio da instituição e é composto, em sua maioria, por funcionários que ocupam o cargo de serviços gerais. Em geral, esse cargo não exige formação específica e alta qualificação profissional, e pode desempenhar funções como serviços de limpeza, portaria, transporte, copeira, entre outras funções similares. Pela simplicidade dos serviços, é característico nesse cargo o baixo grau de instrução e experiência.

Analisando esse contexto, é possível dizer que esse trabalhador quando ajuíza uma reclamatória trabalhista tem um conhecimento das causas, rotinas de trabalho, políticas da empresa, e também conhecimento de outras reclamatórias sofridas pela Instituição contra o setor em questão. Esse fato é nitidamente percebido quando são analisados os pedidos nas reclamatórias trabalhistas contra esse 
setor, que por vezes se repetem e se assemelham nas circunstâncias causadoras. Nesse setor, os cargos que ajuizaram reclamatórias trabalhistas foram serviços gerais, eletricista e copeira. Os funcionários que ocupam o cargo de serviços gerais desempenham funções como limpeza do campus, banheiros, salas, organização e transportes de móveis e documentos para eventos, entre outras atividades similares. Os eletricistas desempenham atividades de instalação e manutenção eletroeletrônica. E as copeiras trabalham, restritamente, fazendo café para os colaboradores da instituição.

No caso dos Setores Administrativos constatou-se um número menor de reclamatórias com $17,01 \%$. Esse resultado se repete nos cursos de graduação, em que esse percentual é dividido pelos diversos setores e coordenadores/supervisores. Vale evidenciar que cada um desses setores é administrado por coordenadores e supervisores distintos, cada qual tem sua forma peculiar de gerir seu ambiente de trabalho. Os setores administrativos servem de suporte aos demais setores da instituição e prestam atendimento aos professores, funcionários, acadêmicos e à comunidade em geral. Nesse setor, os cargos que ajuizaram reclamatórias trabalhistas foram gerente, analista administrativo, assistente de laboratório, assistente administrativo e auxiliar de escritório. $\mathrm{O}$ cargo de gerente demanda responsabilidades específicas de gerenciamento, os cargos de analista administrativo, assistente administrativo e auxiliar de escritório desempenham atividades administrativas e diferenciam-se pelas responsabilidades designadas ao cargo. O cargo de assistente de laboratório desempenha atividades relacionadas à área de química em laboratórios.

Diante das características apresentadas, é possível dizer que as reclamatórias trabalhistas são oriundas das características do ambiente de trabalho, do profissional, da empresa e das relações geradas por estes, que, em conjunto, podem resultar de alguma forma em relacionamentos insatisfatórios entre empregado e empregador.

\section{b) Pedidos Indenizatórios}

Os pedidos indenizatórios que serão apresentados a seguir são oriundos das causas trabalhistas ajuizadas pelos setores apresentados no tópico anterior. Para compreender os detalhes destas reclamatórias, foi necessário analisar o conteúdo de cada processo e listar a frequência das causas e os motivos pelos quais provocaram os colaboradores da instituição em estudo a ajuizarem tais reivindicações.

A tabela 2 apresenta os pedidos indenizatórios relatados nas reclamatórias trabalhistas ajuizadas contra a instituição; a frequência com que foram citados e os motivos que levaram o colaborador a requerer tal direito. 
Tabela 2 - Pedidos indenizatórios

\begin{tabular}{|c|c|c|}
\hline Causas & Freq. & Motivos \\
\hline Horas extras & 19 & $\begin{array}{l}\text { a) Professores reivindicam o pagamento de horas de participação } \\
\text { em reuniões, saída de campo e viagens. } \\
\text { b) Demais cargos: realização de horas extras e não pagamento em } \\
\text { folha é realizado política de banco de horas para compensação. }\end{array}$ \\
\hline Adicional de insalubridade & 13 & $\begin{array}{l}\text { a) Professores: requerido pelos que lecionavam em locais } \\
\text { insalubres como laboratórios. } \\
\text { b) Funcionário apoio logístico: requerido pela limpeza de } \\
\text { banheiros. Nesse caso, a avaliação dos locais insalubres era } \\
\text { realizada por empresa terceirizada, e de acordo com esta o } \\
\text { adicional não era devido. } \\
\text { c) Funcionários administrativos: solicitação de majoração do } \\
\text { adicional pago em folha de pagamento. }\end{array}$ \\
\hline Dano moral & 10 & $\begin{array}{l}\text { Mencionado por funcionários que sentiram sua moral de alguma } \\
\text { forma violada, por sofrer alguma situação de constrangimento, ou } \\
\text { por acharem que sofreram algum tipo de discriminação ou } \\
\text { perseguição. }\end{array}$ \\
\hline Reintegração ao quadro funcional & 9 & $\begin{array}{l}\text { Solicitado pelos colaboradores que entenderam que sua demissão } \\
\text { foi injusta, e que fazem jus ao retorno ao cargo com todos os } \\
\text { benefícios adquiridos até a data do seu desligamento. }\end{array}$ \\
\hline Remuneração das férias & 6 & $\begin{array}{l}\text { Citada como paga com atraso, pelo fato de apenas o } 1 / 3 \text { de férias } \\
\text { ter sido pago antecipadamente ao gozo das férias (este pagamento } \\
\text { era realizado conforme acordo coletivo de trabalho, presente na } \\
\text { Convenção Coletiva). }\end{array}$ \\
\hline FGTS & 5 & $\begin{array}{l}\text { Solicitados depósitos de meses que não apareciam nos extratos } \\
\text { dos órgãos responsáveis. A comprovação é realizada } \\
\text { apresentando a GFIP e a relação de empregados. }\end{array}$ \\
\hline
\end{tabular}

Solicitado por colaboradores que tinham intervalo superior ao

Intervalo intrajornada

4 permitido pela CLT que é de 2 (duas) horas. Porém a empresa

possuí acordo coletivo de trabalho com o sindicato para
ampliação desse intervalo, podendo o intervalo ser de até 4 (quatro) horas.

Solicitado por colaboradores que por algum motivo não

Bolsa de estudo conseguiram o benefício da bolsa fornecido pela instituição, e por colaboradores que faziam jus a estabilidade e o pedido foi para concessão de bolsa até o término do período.

Citado pelo fato da empresa possuir um plano de carreira em que para um novo enquadramento, é necessário o candidato preencher

Enquadramento retroativos 3 os requisitos estipulados no plano e apresentar comprovação por escrito das informações prestadas. Sem a comprovação por escrito não é possível a concretização do pedido de enquadramento.

Refere-se aos colaboradores que foram desligados em um prazo

Pagamento de diferenças salariais 3 inferior a 60 dias do reajuste salarial, que ocorre no dia $1^{\circ}$ de março, ou a colaboradores que solicitavam diferenças salariais referente a enquadramentos não realizados pela instituição.

\begin{tabular}{lcl}
\hline Adicional noturno & 2 & $\begin{array}{l}\text { Solicitado por professores que lecionam no período noturno a } \\
\text { partir das 22 horas. }\end{array}$ \\
\hline Adicional de periculosidade & 2 & $\begin{array}{l}\text { Requerido por funcionários que estavam em algum momento em } \\
\text { contato indireto com redes elétricas. }\end{array}$ \\
\hline Equiparação salarial & 2 & $\begin{array}{l}\text { Solicitada por funcionários que exerciam a mesma função, porém } \\
\text { recebiam salários diferentes. }\end{array}$ \\
\hline Nulidade da demissão & 2 & $\begin{array}{l}\text { Solicitado por colaboradores que pediam a anulação da rescisão } \\
\text { de contrato, por acharem esta foi realizada de forma incorreta. }\end{array}$ \\
\hline $\begin{array}{l}\text { Pagamento de verbas rescisórias } \\
\text { devido dispensa ao terminar o ano } \\
\text { letivo }\end{array}$ & $\begin{array}{l}\text { Solicitado por professores desligados no mês de dezembro, no } \\
\text { término das aulas, o colaborador solicita o pagamento de salários } \\
\text { até o mês de fevereiro, quando se inicia novamente o ano letivo. }\end{array}$ \\
\hline $\begin{array}{l}\text { Adicional de gratificação de } \\
\text { função }\end{array}$ & 1 & $\begin{array}{l}\text { Solicitado por colaborador que afirmava ser responsável pelo } \\
\text { setor em que trabalhava. Entretanto, o mesmo era responsável por } \\
\text { uma determinada função do setor e não pela equipe de trabalho. }\end{array}$ \\
\hline Pagamento de pensionato & 1 & $\begin{array}{l}\text { Solicitados em uma mesma reclamatória, por um funcionário que } \\
\text { sofreu um acidente de trabalho e solicitou indenização por este e }\end{array}$ \\
\hline
\end{tabular}

Fonte: Dados da pesquisa. 
Ao analisar a tabela 2, foi possível constatar que a maioria dos casos poderiam ser evitados se houvesse o esclarecimento aos colaboradores dos procedimentos e normas que deveriam ser adotados, evitando maus entendidos e conflitos posteriores, e estabelecendo relações de confiança entre empregado e empregador. Vale evidenciar que, para a existência de um clima harmonioso numa organização, os gestores precisam gerenciar permanentemente os conflitos, pois a solução tardia pode influenciar, consideravelmente, na produtividade e no bom desempenho da empresa.

Nas causas apresentadas na tabela 2, ressalte-se que os itens como horas extras, adicional de insalubridade, remuneração das férias e intervalos intrajornada, que obtiveram maiores frequências de citações, podem ser evitados com a aplicação da legislação como procedimento padrão e monitoramento constante desses.

Outros itens como pedidos de reintegração ao quadro funcional e dano moral são mais abstratos e necessitam de uma atenção específica nas relações de trabaIho, principalmente, entre gestores e subordinados. Por serem causas abstratas e mais difíceis de serem identificadas com antecedência, como prevenção, podem ser utilizadas medidas como treinamento e capacitação dos colaboradores com cargo de gerência ou supervisão com foco no lado humanístico da gestão de pessoas.

Ainda vale evidenciar que, em alguns itens como FGTS e encargos previdenciários, a empresa cumpre a legislação e está em dia com suas obrigações, sendo assim, esses itens não necessitam de outros tipos de medidas de prevenção, basta a continuação do que está sendo aplicado.

c) Procedência das Causas

Nesta pesquisa, foram analisadas trinta e cinco reclamatórias trabalhistas ajuizadas contra a empresa em estudo. Dessas, nove tiveram que ser separadas, pois houve acordo ou conciliação - nesse caso, não é possível analisar a procedência das causas separadamente, pois é acordado um valor total para o processo, e não há o julgamento das causas. A avaliação foi realizada com doze reclamatórias em que já houve a sentença e é possível identificar a procedência das causas ou não, porém não se teve acesso aos valores das causas julgadas procedentes, pois estes são divulgados após o cálculo da sentença. Ainda assim, vale ressaltar que o conhecimento desse item é importante para identificar o total de passivos trabaIhistas que na empresa está sendo gerado. 
Tabela 3 - Procedência das causas

\begin{tabular}{llll}
\hline Causas & Total & Procedente \\
\cline { 2 - 3 } & Sim & Não \\
\hline Horas extras & 6 & 4 & 2 \\
Reintegração ao quadro funcional & 5 & 3 & 2 \\
Dano moral & 4 & 1 & 3 \\
Adicional de insalubridade & 3 & 1 & 2 \\
Remuneração das férias & 2 & 2 & 1 \\
Nulidade da demissão & 2 & 1 \\
Adicional noturno & 2 & 1 \\
Adicional de gratificação de função & 1 & 1 \\
Enquadramento retroativo & 1 & 1 \\
Descanso Semanal Remunerado & 1 & 1 \\
Pagamento de verbas rescisórias devido dispensa ao terminar o ano letivo & 1 & 1 \\
Dano material & 1 & 1 \\
Ressarcimento de despesas médicas e medicamentos & 1 & 1 \\
Pagamento de pensionato & 1 & 1 \\
Encargos previdenciários & 1 & 1 \\
FGTS & 1 & 1 \\
Vale transporte & 1 & 1 \\
Bolsa de estudo & 1 & 1 \\
Total & 1 & $\mathbf{3 5}$ & $\mathbf{1 4}$ \\
\hline
\end{tabular}

Fonte: Dados da pesquisa.

A tabela 3 mostra o total de causas citadas nos 12 processos em que já houve a sentença e as causas que foram julgadas procedentes ou não.

Analisando a tabela 3, foi possível perceber que a Instituição tem se manifestado de forma positiva na defesa das reclamatórias, sendo que do total de 35 causas, 21 foram julgadas improcedentes. O maior cuidado que a organização deve ter é com as causas em que houve um número maior de procedência, como horas extras, reintegração ao quadro funcional, remuneração das férias e pagamento das verbas rescisórias devido à dispensa ao terminar o ano letivo. A forma de prevenção destas causas e apresentação das medidas que a empresa já tomou, serão apresentadas no capítulo de discussão da pesquisa.

\section{d) Custos Gerados Pelas Reclamatórias}

Nesta seção foram analisadas as reclamatórias trabalhistas que tiveram acordos ou conciliação, identificando o custo total de cada processo, incluindo o valor do acordo e os valores gastos no desenrolar do processo, conforme demonstra a tabela 4.

Analisando a tabela 4, é possível perceber que a diferença entre o valor do pedido inicial e o valor que é gasto pela empresa é grande. Porém, o valor que está sendo gasto é um valor alto e que poderia ser melhor utilizado dentro da 
instituição com melhorias e ajustes para o bem-estar de todos os colaboradores. Os custos aqui analisados são os diretos, lembrando que, além desses, tem-se os custos indiretos, como o tempo gasto pelos funcionários envolvidos no processo de defesa da reclamatória.

Tabela 4 - Custos de reclamatórias trabalhistas com acordos ou conciliação

\begin{tabular}{lllll}
\hline $\mathbf{N}^{\mathbf{0}}$ & Valor do pedido inicial & Valor do acordo & Custas do processo & Custo total do processo \\
\hline 1 & $\mathrm{R} \$ 45.000,00$ & $\mathrm{R} \$ 12.000,00^{*}$ & $\mathrm{R} \$ 3.000,00$ & $\mathrm{R} \$ 15.000,00$ \\
2 & $\mathrm{R} \$ 25.000,00$ & $\mathrm{R} \$ 15.000,00$ & $\mathrm{R} \$ 800,00$ & $\mathrm{R} \$ 15.800,00$ \\
3 & $\mathrm{R} \$ 25.000,00$ & $\mathrm{R} \$ 8.500,00$ & $\mathrm{R} \$ 2.859,64$ & $\mathrm{R} \$ 11.359,64$ \\
4 & $\mathrm{R} \$ 25.000,00$ & $\mathrm{R} \$ 5.000,00$ & $\mathrm{R} \$ 0,00$ & $\mathrm{R} \$ 5.000,00$ \\
5 & $\mathrm{R} \$ 90.000,00$ & $\mathrm{R} \$ 15.000,00$ & $\mathrm{R} \$ 800,00$ & $\mathrm{R} \$ 15.800,00$ \\
6 & $\mathrm{R} \$ 22.000,00$ & $\mathrm{R} \$ 8.000,00$ & $\mathrm{R} \$ 0,00$ & $\mathrm{R} \$ 8.000,00$ \\
7 & $\mathrm{R} \$ 24.000,00$ & $\mathrm{R} \$ 12.000,00$ & $\mathrm{R} \$ 0,00$ & $\mathrm{R} \$ 12.000,00$ \\
8 & $\mathrm{R} \$ 30.000,00$ & $\mathrm{R} \$ 6.000,00$ & $\mathrm{R} \$ 2.000,00$ & $\mathrm{R} \$ 8.000,00$ \\
9 & $\mathrm{R} \$ 25.000,00$ & $\mathrm{R} \$ 10.000,00$ & $\mathrm{R} \$ 3.541,64$ & $\mathrm{R} \$ 13.541,64$ \\
& $\mathrm{R} \$ \mathbf{3 1 1 . 0 0 0 , 0 0}$ & $\mathbf{R} \mathbf{7 9 . 5 0 0 , 0 0}$ & $\mathbf{R} \$ \mathbf{1 3 . 0 0 1 , 2 8}$ & $\mathbf{R} \mathbf{9 2 . 5 0 1 , 2 8}$ \\
\hline
\end{tabular}

*Observação: não incluso a concessão de bolsa aos dependentes de julho/2010 a dezembro/2011.

Fonte: Dados da pesquisa.

Vale ressaltar que, do total das trinta e cinco reclamatórias, em apenas nove houve a possibilidade de acordo ou conciliação; ou seja, em apenas $25,71 \%$ dos casos, isso pelo fato da disparidade entre o valor pedido e o valor que a instituição está disposta a pagar.

Outra discrepância que deve ser mencionada é entre o valor do pedido e o valor do acordo, como na reclamatória em que o pedido inicial é de $\mathrm{R} \$ 90.000,00$ e o acordo realizado foi de $\mathrm{R} \$ 15.000,00$. Isso acontece porque é comum agregar vários pedidos na mesma reclamatória, pois se a empresa não possuir provas, pode ter que realizar novamente o pagamento das causas reclamadas.

A tabela 5 demonstra o valor total do pedido inicial do restante das reclamatórias que não tiveram acordo, ou seja, as que estão em andamento e as que já tiveram sentença. E o custo total que foi gasto até o momento por custas dos processos.

Tabela 5 - Valores das reclamatórias trabalhistas em andamento

\begin{tabular}{lll}
\hline Total de reclamatórias & Valor do pedido inicial & Custa total do processo \\
\hline 26 & $\mathrm{R} \$ 896.000,00$ & $\mathrm{R} \$ 93.811,04$ \\
\hline
\end{tabular}

Fonte: Dados da pesquisa. 
Analisando a tabela 5, é possível identificar que o valor gasto em média por ano aproxima-se de $\mathrm{R} \$ 50.000,00$. Vale ressaltar que esse valor é apenas o total gasto com custas dos processos, que não constam aqui os valores das reclamatórias que tiveram acordos, que foram citadas anteriormente. Não estão inclusos também os custos indiretos, que são os custos relacionados ao processo, como o tempo gasto pelos colaboradores para levantamento das provas, elaboração da defesa da instituição e atuação como preposto, testemunhas ou advogados. Esses custos são mais difíceis de mensurar e é por esse fato que é difícil conhecer o seu valor. Porém, é de conhecimento da instituição que determinados processos demandam grande movimentação de diversos setores, que necessitam trabalhar juntos para que a defesa seja elaborada de forma ágil e para que sejam levantadas todas as provas necessárias inerentes ao processo.

Por fim, analisando de forma totalizada, somando os custos diretos gastos com os acordos e com custas dos processos, chega-se a uma média de $\mathrm{R} \$ 93.156,16$ por ano - um valor alto, considerando-se que a empresa em questão está em um processo de redução de custos. Vale ressaltar que os passivos trabalhistas são itens inerentes à vida empresarial, mas que podem ser evitados com ações estratégicas de prevenção e controle de reclamatórias. Ademais, em qualquer empresa é interessante que os custos de passivos trabalhistas sejam o menor possível.

\section{DISCUSSÃO DOS RESULTADOS}

Segundo Metz (2003), as reclamatórias trabalhistas podem surgir por diferentes fatores: a) descumprimento ou mau cumprimento da legislação vigente, seja por desconhecimento ou por opção da empresa, como, por exemplo, nos casos de redução de custos; b) conflito na relação entre empregado e empregador, gerando situações desconfortantes e podendo causar revolta do empregado; c) situações inseguras de equipamento, ferramentas, ambiente, comportamento e aspecto legal, o que pode ocasionar os itens anteriores, descumprimento da legislação e conflito nas relações.

Nesse estudo, foi possível identificar que as causas com maior incidência foram as horas extras e o adicional de insalubridade que se enquadram no item $a$ citado por Metz (2003), em que os pedidos foram reivindicados pelo fato da legislação não estar sendo aplicada de forma correta. Sendo assim, a resolução dessas causas é a aplicação das leis, o que já deveria ter sido evitado com medidas de controle e gestão das situações de risco. No item $b$, enquadram-se as causas como dano moral e reintegração ao quadro funcional, que são causas mais difíceis 
de se identificar e resultam de conflitos mal resolvidos dentro da organização, onde a atenção deve ser com as relações de trabalho estabelecidas. E no item $c$ se encaixam as causas como acidente de trabalho e adicional de periculosidade, que podem surgir por situações inseguras, como uso incorreto de EPIs ou o não uso desses. Vale evidenciar que, nesse caso, a empresa criou no ano de 2010 o Setor de Segurança e Medicina do Trabalhador, que está trabalhando de forma ativa na prevenção de acidentes e situações que poderiam colocar o colaborador em risco, reduzindo, consideravelmente, as causas ligadas a esse item.

As consequências das reclamatórias trabalhistas podem exceder os limites da organização, trazendo prejuízos financeiros nas relações com a sociedade, na imagem que a empresa transmite e no clima organizacional vivenciado pela organização no seu dia a dia. Segundo Almeida (2006), inconscientemente os empregados alimentam expectativas psicológicas por fazerem parte da empresa, e, em algum momento, essas necessidades podem ser incompatíveis com o que a instituição tem a oferecer, causando assim, uma possível fonte de conflitos organizacionais que podem ser reduzidas com informações claras e constantes, sobre todos os assuntos acerca das relações de trabalho. Apesar das desvantagens trazidas pelos conflitos, é necessário lembrar que esses geram mudanças e possíveis inovações, que podem ajudar a disseminar a harmonia nas relações dentro da empresa, e que a partir dessas situações poderão surgir informações que antes não eram vistas.

Dentre os resultados obtidos na pesquisa, é importante ressaltar o valor dos custos diretos levantados que chegam à média de $\mathrm{R} \$ 93.156,16$ por ano, sem contar os custos indiretos gastos no desenrolar do processo, como o tempo despendido pelos colaboradores envolvidos. Vale ressaltar que este é um valor alto, considerando que a instituição no momento está buscando a redução de custos. É possível dizer que a empresa poderia investir esses valores em benefícios e melhorias para os colaboradores, motivando-os e incentivando um clima harmonioso dentro da organização, ou em políticas de prevenção de reclamatórias trabalhistas.

Após análise dos dados obtidos na pesquisa, foi possível entender os motivos que levam esses colaboradores a reivindicar seus direitos judicialmente, e diante desse contexto algumas alternativas poderiam ser implantadas como: a) capacitação para desenvolvimento dos profissionais; b) cuidados voltados para a saúde e qualidade de vida; c) criação de benefícios com foco na família do trabalhador; d) atitudes e comportamentos por parte dos gestores de forma a prevalecer o respeito e a empatia. Esses são itens que poderiam ajudar a reduzir o número de reclamatórias ajuizadas contra a instituição em questão. 


\section{CONSIDERAÇÕES FINAIS}

O objetivo geral desta pesquisa foi conhecer as causas das reclamatórias trabalhistas e os motivos que levaram os colaboradores a reivindicar seus direitos judicialmente. Foi possível perceber que de forma geral a maioria das causas poderiam ser evitadas com pequenas atitudes que demonstram atenção ao colaborador e a valorização deste. As situações geradoras de conflitos e desconfiança por parte dos trabalhadores, muitas vezes, são imperceptíveis na ocasião, mas refletem em algum momento, na insatisfação e revolta por parte do empregado em relação à instituição, ocasionando disparidade nas relações de trabalho.

Diante do exposto, nasce a necessidade do foco na gestão de pessoas e das relações de trabalho, entre empregado e empregador, desde o momento da admissão até o desligamento do colaborador, para que este tenha sempre uma imagem positiva da empresa.

A respeito das causas das reclamatórias foi identificado que a maioria dos itens necessitam apenas de revisão de procedimentos e monitoramento, como é o caso das horas extras, adicional de insalubridade e remuneração das férias. Os pedidos de reintegração ao quadro funcional e dano moral, são itens que ainda necessitam serem trabalhados, principalmente, a forma com que a gestão de pessoas e as relações de trabalho são conduzidas e estabelecidas dentro da organização. Em alguns itens existem ainda aqueles em que não há o que fazer para prevenir essas causas, como é o caso dos pedidos de FGTS e encargos previdenciários. Nesse caso, foi identificado que a empresa cumpre a legislação, porém os pedidos muitas vezes ocorrem pela má fé de ex-colaboradores.

Para controle e gestão desses procedimentos é necessário integrar novos processos à cultura da instituição, a fim de normatizar e padronizar algumas rotinas como forma de minimizar os conflitos internos. Referente a procedência das causas é visível que a instituição está bem representada, sendo predominante as causas julgadas improcedentes. Porém, é conveniente que a instituição se preocupe, também, com a prevenção dessas causas, o que além de evitar custos e maiores transtornos, demonstrará preocupação com a imagem que está transmitindo aos seus colaboradores.

Referente aos custos, foi possível concluir que a diferença entre o valor do pedido inicial e o valor que a instituição desembolsa é discrepante, sendo isso um fator que leva a crer que ela está realizando eficaz defesa perante à justiça. Porém, é interessante que os custos com passivos trabalhistas sejam minimizados 
ao longo do tempo, pois além de influenciar no desempenho financeiro da instituição, também impacta no clima organizacional como um todo. Vale ressaltar que para o levantamento total dos custos, houve uma limitação na pesquisa, por não se ter acesso ao valor das sentenças das reclamatórias que já foram julgadas. Para pesquisas futuras, sugere-se a aplicação deste estudo com outras instituições, sejam elas de ensino ou não, como forma de ampliar a compreensão sobre o tema.

\section{REFERÊNCIAS}

ALMEIDA, Marcus Garcia de. Pedagogia empresarial: saberes, práticas e saberes. Rio de Janeiro: Brasport, 2006.

BERNSTEINS, P. L. Desafio aos deuses: a fascinante história do risco. Rio de Janeiro: Elsevier, 1997.

BORGES, M. E. S. Trabalho, gestão de si: para além dos "recursos humanos". Cadernos de Psicologia Social do trabalho, São Paulo, v. 7, p. 41-49, 2004. Disponível em: <http://pepsic.bvsalud.org/scielo.php?pid=S151637172004000100005\&script=sci_arttext>. Acesso em: 4 maio 2013.

COSTA, A. C.; FERRARI, I.; MARTINS, M. R. Consolidação das Leis do Trabalho. 34. ed. São Paulo: LTr, 2007.

FENASERA. Informações trabalhistas e previdenciárias. jun, 2012. Disponível em: $<$ http://www.fenasera.org.br/detalhe_saibamais.php?id_noticia=6>. Acesso em: 25 jun. 2012.

GARCIA, R. G. Rotinas trabalhistas: problemas práticos na atuação diária. São Paulo: Atlas, 1999.

GONÇALVES, G. Resumo prático de folha de pagamento. 3 ed. Curitiba: Juruá, 2000. INEP - Instituto Nacional de Estudos e Pesquisas Educacionais Anísio Teixeira. Sinopse Estatística da Educação Superior 2015. Brasília: Inep, 2016. Disponível em: $<$ http://portal.inep.gov.br/basica-censo-escolar-sinopse-sinopse>. Acesso em 10 mar. 2017.

JORGE, M. S. B. et. al. Gestão de Recursos Humanos nos Centros de Atenção Psicossocial no contexto da política de desprecarização do trabalho no Sistema Único de Saúde. Texto \& Contexto Enfermagem, Florianópolis, v. 16, n. 3, p. 417-425, 
jul./set, 2007. Disponível em: <http://www.scielo.br/scielo.php?script=sci_ arttext\&pid=S0104-07072007000300006>. Acesso em: 4 mai. 2013.

JOSKO, J. M. B. Gestão de pessoas em tecnologia da informação - uma visão perspectiva das abordagens. 103p. Dissertação (Mestrado Profissional) Programa de Pós-Graduação em Ciências da Computação Universidade de Campinas (UNICAMP) - Instituto de Computação, 2004. Disponível em: <http:// www.bibliotecadigital.unicamp.br/document/?code=vtls000332728>. Acesso em: 5 mai. 2013.

LÓRIO, C. S. Manual de administração de pessoal. 12. ed. São Paulo: Senac, 2008.

MACHADO, N. Identidade e Imagem: elementos formadores da reputação. In: DORNELLES, M. G. (org.). Relações Públicas: quem sabe, faz e explica. Porto Alegre: EDIPUCRS, 47-62 p, 2007.

MARRAS, J. P. Administração de recursos humanos: do operacional ao estratégico. 11. ed. São Paulo: Futura, 2005.

METZ, S. O gerenciamento de riscos na prevenção de perdas trabalhistas: um estudo de caso do Grupo Eberle Mundial. 173 p. Dissertação (Mestrado Profissional) Universidade Federal do Rio Grande do Sul, Porto Alegre, 2003.

OLIVARES, J. E. L. Negociação para configuraro desenho da estrutura organizacional em rede, 2012. Disponível em: <http://profjayrfigueiredo.com.br/GON_AC_09. pdf $>$. Acesso em 26 out. 2012.

PONTELO, J.; CRUZ, L. Gestão de pessoas: manual de rotinas trabalhistas. Brasília: SENAC, 2006.

SANTOS, P. S. M. Gestão de riscos empresariais. Osasco: Novo Século, 2002.

SIQUEIRA, M. M. Gestão de recursos humanos: o enfoque das relações de trabalho. In: GOULART, Íris Barbosa; SAMPAIO, Jader dos Reis (orgs). Psicologia do trabalho e gestão dos recursos humanos: estudos contemporâneos. São Paulo: Casa do Psicólogo, 1998. p. 69-83.

ZANCHETTA, V. R. Principais causas de ações indenizatórias contra os bancos: algumas recomendações jurídico-administrativas. 2007. 124 p. Monografia (Pós-Graduação em Administração) - Universidade Federal do Rio Grande do Sul, Porto Alegre. 